\title{
The Role of Aryl Hydrocarbon Receptor (AHR) and AHR-Interacting Protein (AIP) in the Pathogenesis of Pituitary Adenomas
}

\author{
Marie-Lise Jaffrain-Rea and Albert Beckers
}

\section{Contents}

Introduction.

Familial Isolated Pituitary Adenomas (FIPA), the AIP Gene and the Expanding Spectrum of AIP-Related Diseases

Clinical Presentation of Patients with a Germline AIP Mutation

Molecular Genetics of AIP..

Lessons from an $\mathrm{AIP}^{+/-}$Mice Model

AIP, AHR and Other AIP-Related Proteins in the Pathogenesis of Pituitary Adenomas Pituitary Expression of AIP

The AIP Protein: From Structure to Function.......... 193

AIP and the Regulation of AHR Signalling ............ 194

AHR and the Pituitary Gland ................................. 194

AHR, the Cell Cycle and Tumorigenesis ................ 195

AHR, AIP and the Modulation of Nuclear

Endocrine Signalling.

AHR and Endocrine Disruption................................. 196

Interactions of AIP and AHR with PPAR $\alpha \ldots \ldots \ldots \ldots . . .197$

AIP, AHR and the Modulation of the cAMP

Pathway

AIP and the RET/Survivin Interaction

Conclusion and Future Perspectives

References

M.-L. Jaffrain-Rea $(\bowtie)$

Department of Biotechnological and Applied Clinical Sciences, University of L'Aquila, via Vetoio, Neuromed Institute Coppito 2, L'Aquila 67100, Italy

e-mail: jaffrain.ml@ libero.it

\section{A. Beckers}

Department of Endocrinology, Centre Hospitalier Universitaire de Liege, Domaine Universitaire du Sart-Tilman, Liege 4000, Belgium

\section{Abstract}

Pituitary adenomas (PA) are common endocrine neoplasia, generally presenting as sporadic diseases, with a multifactorial pathogenesis including somatic mutational events in cancer-related genes. However, genetic predisposition can currently be recognized in $>5 \%$ of affected patients, mostly involving the Multiple Endocrine Neoplasia type 1 (MEN1) gene and the more recently identified Aryl hydrocarbon receptor Interacting Protein $(A I P)$ gene, both being tumor-suppressor genes. Germline mutations in the AIP gene can be observed in a FIPA (Familial Isolated Pituitary Adenoma) context, but also in a minority of young patients with an apparently sporadic disease. Although the role of AIP in the pathogenesis of PA remains largely unknown, it is known to be mainly expressed by somatototrophs, with a frequent loss of expression in most AIP-mutated PA and in invasive somatotropinomas. The best characterized function of AIP is to stabilize the Aryl hydrocarbon Receptor, also known as the dioxin receptor, in the cytoplasm, but multiple interactions of AIP with other proteins involved in endocrine signalling and the regulation of cell cycle and apoptosis have been reported. In this chapter, current knowledge about the possible role of AhR and additional AIPrelated proteins in pituitary tumorigenesis will be analysed. 


\section{Introduction}

Pituitary adenomas (PA) are among the most frequent endocrine tumors, with a clinical prevalence approaching 1/1,000 inhabitants in recent studies (Beckers 2010). PA are typically benign, but extrasellar extension is frequent and invasive features towards surrounding structures (i.e., the dura, sellar bone, cavernous sinus) increase with tumor size. Malignant evolution is extremely rare and defined by extra-pituitary dissemination. PA are classified into secreting and non-secreting according to the presence or absence, respectively, of pituitary hormone hypersecretion. Their pathogenesis is multifactorial and, despite common monoclonality suggesting the presence of an initiating molecular event, they are usually sporadic, with a complex pathogenesis including genetic and epigenetic events and a variety of alterations in intra- and extra-cellular signalling (Asa and Ezzat 2009).

Inherited genetic susceptibility is being increasingly recognized and is currently estimated to involve at least $5 \%$ of PA patients. Arguments suggesting inherited susceptibility are: (1) the presence of extra-pituitary manifestations suggestive of a syndromic disease, namely the Multiple Endocrine Neoplasia type 1 syndrome (MEN1), which accounts for nearly 3\% of PA, rarely the Carney's complex (CNC) or McCune Albright syndrome (MAS), (2) the presence of an isolated familiarity for PA, which was first recognized for patients with acromegaly (Isolated Familial Somatotropinoma - IFS), subsequently shown to potentially involve all PA phenotypes (Familial Isolated Pituitary Adenoma- FIPA) and also represents $2-3 \%$ of PA patients, (3) an early onset of the disease, especially in children and adolescents, who represent about only $10 \%$ of PA patients but are more likely to be syndromic or familial. We have recently reviewed the clinical presentation, molecular genetics and screening implications of the syndromic conditions cited hitherto (Jaffrain-Rea et al. 2010a) and we will focus our attention on the most relevant aspects of the FIPA syndrome and on the potential pathogenetic implications of the Aryl hydrocarbon receptor Interacting Protein $(A I P)$ gene, which currently explains a significant subset of FIPA kindreds and has been involved in a minority of early onset PA with an apparently sporadic presentation.

\section{Familial Isolated Pituitary Adenomas (FIPA), the AIP Gene and the Expanding Spectrum of AIP-Related Diseases}

Familial tumors offer unique opportunities to characterize genes involved in their pathogenesis and, indirectly, in the normal physiology of the corresponding tissue. Familial forms of pituitary tumors occurring in association with hyperparathyroidism and pancreas endocrine neoplasia have defined the MEN1 syndrome and contributed to the identification of a disease locus in 11q13, leading in 1997 to the identification of the MEN1 gene, a major tumor suppressor gene. As recently reviewed by Thakker (2010), hundreds of inactivating mutations of the MEN1 gene could then be identified in MEN1 kindreds, genetic mice models have further supported the role of the MEN1 gene in disease susceptibility, and the molecular mechanisms involved in MEN1-related tumorigenesis are being progressively elucidated. Kindreds with isolated somatotropinomas (IFS) were already recognized to occur outside of the MEN1 syndrome and later confirmed to be unrelated to MEN1 gene mutations. Nonetheless, linkage to the $11 \mathrm{q} 13$ region could be established in some cases by Galdelha et al. (1999), with documented LOH in the corresponding tumors suggesting the presence of a second tumor suppressor gene in this region. Recently, two important publications have lead to significant progress in the elucidation of inherited predisposition to PA linked to a new tumor suppressor gene in 11q13: (1) Vierimaa et al. (2006) identified germline inactivating mutations of the AIP gene in two large Finnish kindreds with GH/PRL-secreting PA and in an Italian IFS family; with somatic $\mathrm{LOH}$ in $11 \mathrm{q} 13$ being confirmed in the corresponding tumors, (2) Daly et al. (2006) characterized 64 kindreds with Familial Isolated Pituitary Adenomas (FIPA) 
collected internationally, comprising both homogenous and heterogeneous families - i.e. expressing a single or multiple PA phenotypes, respectively - , the homogenous somatotropinoma/IFS subgroup representing $30 \%$ of the whole series. Soon after, the same group reported germline mutations in the AIP gene in $15 \%$ of FIPA kindreds, and up to $50 \%$ of those with homogeneous somatotropinomas/IFS, respectively (Daly et al. 2007).

\section{Clinical Presentation of Patients with a Germline AIP Mutation}

The great interest in AIP as a new player in pituitary tumorigenesis has lead to a number of genetic studies on FIPA and sporadic PA allowing, within a 4 years period, to delineate the most common characteristics of $A I P^{\text {mut }}$ patients and tumors, and to evaluate their therapeutic outcome. In a recent collaborative work collecting 96 AIP $^{\text {mut }}$ patients worldwide (Daly et al., 2010), $60 \%$ cases occurred in a documented FIPA setting and $40 \%$ were apparently sporadic, respectively. Somatotropinomas were by far the most prevalent phenotype ( $\sim 80 \%)$, followed by prolactinomas $(\sim 15 \%)$, NFPA, and rare corticotrophinomas and thyreotrophinomas. The median age at diagnosis and at first symptoms were 23 and 18 years overall, implying that half of the patients developed a symptomatic disease during childhood or adolescence. In this study, $75 A I P^{\text {mut }}$ somatotropinomas were compared to 232 non$A I P^{m u t}$ somatotropinomas confirmed genetically, providing final evidence that the presence of germline AIP changes in acromegalics was associated with a much earlier age at diagnosis (20 years earlier) and a more aggressive course of the disease. The early onset translated into an unusual rate of overt or incipient gigantism (32 vs 6\% in control cases). A male predominance was observed $(>60 \%)$ and all giant were males. Somatotropinomas in the AIP ${ }^{m u t}$ group were typically macroadenomas ( $>90 \%)$ and, as compared with non-AIP ${ }^{m u t}$ somatotropinomas, they had significantly larger maximal tumor diameter. At diagnosis, AIP ${ }^{m u t}$ acromegalics had higher median plasma GH levels and presented twice more frequently with PRL hypersecretion than non-AIP $P^{\text {mut }}$ patients. Disease control in $A I P^{m u t}$ somatotropinomas was also more difficult to achieve, with a lower decrease in GH/IGF-1 on somatostatin analogues therapy and a more frequent need for multiple surgeries and/or radiotherapy. Prolactinomas in $A I P^{m u t}$ patients were also recognized essentially in males ( $>75 \%)$, with a median age at diagnosis of 22 years, $~ 50 \%$ occurred in a familial setting and most were large and invasive, with an unusual rate of resistance to dopamineagonist therapy (50\%).

\section{Molecular Genetics of AIP}

Ozfirat and Korbonits (2010) have reviewed nearly 50 AIP mutations identified so far by international cohorts, reported by the Finnish, Belgian and British groups and additional family case reports. Most mutations are distributed through the entire coding sequence (6 exons), 60-70\% are truncating - with a similar frequency for nonsense and frameshift mutations, followed by splice site mutations - and $>20 \%$ are missense. The remaining alterations include large deletions and some changes of uncertain biological significance, such as rare polymorphisms and intron variants not expected to alter splicing. Promoter mutations have also been exceptionally reported. Some mutations have been encountered more frequently, such as $A I P^{\mathrm{Q} 14 \mathrm{X}}$ - a founder mutation in Finland-, $A I P^{\mathrm{R} 304 \mathrm{X}}$ - the most frequently reported in Europe, with a partial founder effect in Italy -, $A I P^{\mathrm{R} 304 \mathrm{Q}}$ - which further indicates codon 304 as a hot mutational spot-, $A I P^{\mathrm{R} 271 \mathrm{w}}$, and $A I P^{\mathrm{R} 81 \mathrm{x}}$. Codon K241 may represent an additional hot spot, with both $A I P^{\mathrm{K} 241 \mathrm{E}}$ and $A I P^{\mathrm{K} 241 \mathrm{X}}$ changes being reported.

The penetrance of germline AIP mutations is incomplete. In FIPA kindreds, due to a still limited knowledge on large $A I P^{\text {mut }}$ kindreds, it is currently but imprecisely estimated around 30\% (15-45\%). Preliminary data on familial screening in apparently sporadic patients indicate that de novo germline AIP mutations are very rare, but most $A I P^{\text {mut }}$ relatives are unaffected. At the moment, AIP can 


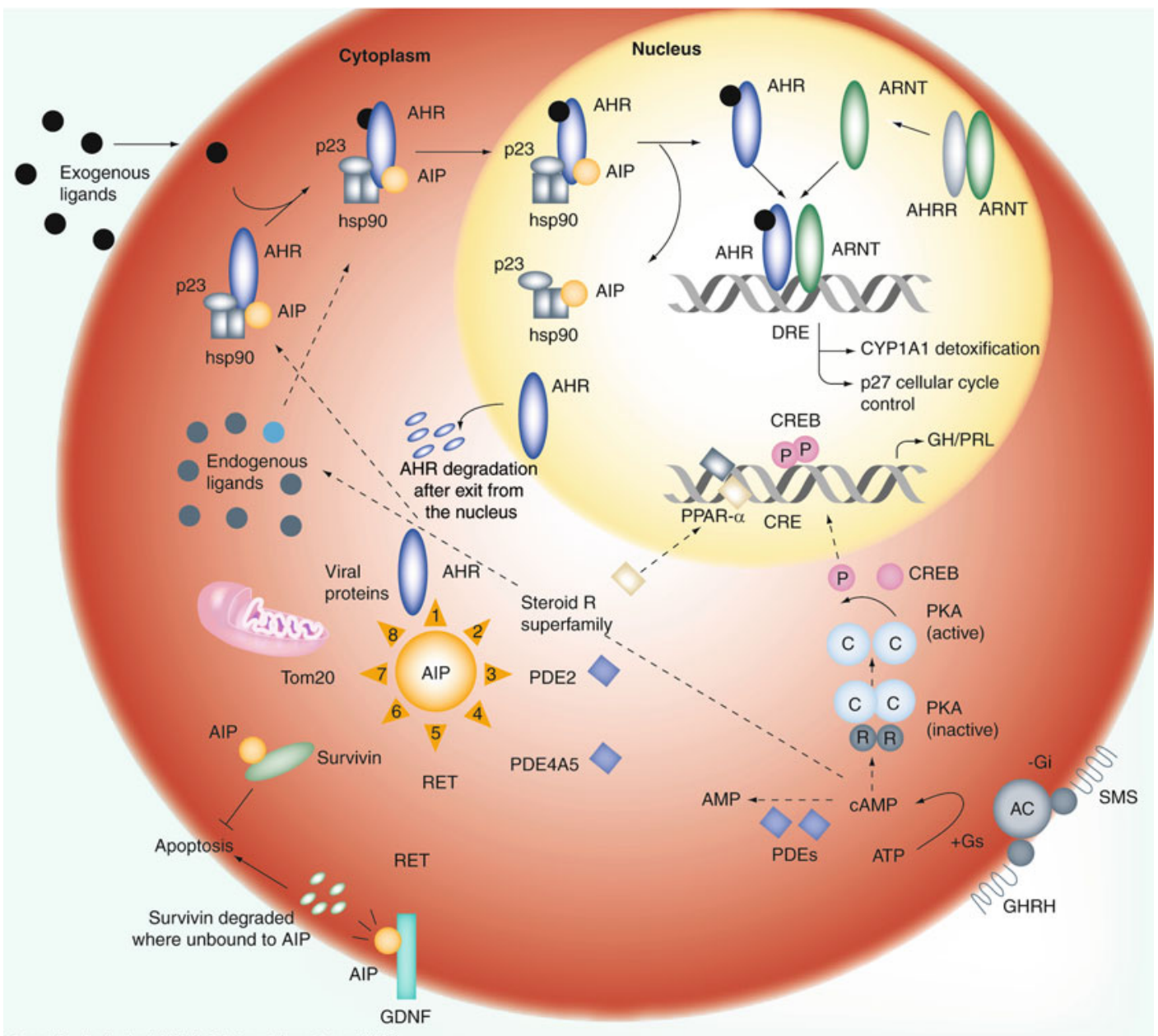

Expert Rev. Endocrinol. Metab. O Future Science Group (2011)

Fig. 21.1 AIP molecular interactions and related pathways. AIP is involved in multiple protein-protein interactions and potential molecular pathways: (1) the transcription factor AhR (Aryl hydrocarbon Receptor, or dioxin receptor) is stabilized by AIP in a cytoplasmic AhR/AIP/hsp90/p23 core complex; upon activation by exogenous AhR moves to the nucleus, heterodimerizes with Ah Receptor Nuclear Translocator (ARNT) and exerts direct transcriptional effects through Dioxin Responsive Elements (DRE) - activation by endogenous ligands (including cAMP) may elicit a different transcriptional response - (2) members of the steroid receptor superfamily include the transcription factor PPAR $\alpha$, the thyroid receptor TR $\beta 1$ and the glucocorticoid receptor, $(3,4)$ Phosphodiesterases PDE2 and PDE4A5 are involved in the regulation of the cAMP concentration. cAMP is produced from ATP by the Adenyl Cyclase (AC), activates the Protein Kinase A (PKA) by binding its regula-

be therefore considered either as a FIPA gene, which can be inherited in a dominant manner with a variable but clinically relevant penetrance, or as tory subunits (RR) and releasing its catalytic subunits (CC); this results in Ser-133 phosphorylation of the cAMP Responsive Elements Binding protein (CREB) and enhanced transcriptional activity through cAMP Responsive Elements (CRE), which are present in GH and PRL gene promoters; (5) the RET proto-oncogene is the tyrosine kinase receptor for the Glial cell line-Derived Neurotrophic Factor (GDNF) family of ligands; binding of AIP to RET prevents the formation of AIP/survivin complexes (6), in the absence of RET, AIP binds survivin, preventing its degradation thus protecting cells from apoptosis. (7) Tom 20 are proteins involved in mitochondrial import and (8) Viral proteins include the Hepatitis B virus X antigen and the Epstein Barr Virus (EBV)-encoded nuclear antigen-3 (EBNA-3). See text for references (NB Authorization to reproduce this figure from Jaffrain-Rea et al. (2010) has been obtained from Expert Reviews in Endocrinology and Metabolism)

a PAP gene, with a low penetrance. These views are not necessarily conflicting since, similarly to disease severity, disease penetrance may vary 
according to the biological effects of distinct mutations on target cells and the presence of genetic or environmental modifiers. The contrast between the frequent severity of the disease and its incomplete or low penetrance differentiates most $A I P^{\mathrm{mu} t}$ kindreds from MEN1 kindreds and should be taken into account for genetic counselling (Jaffrain-Rea et al. 2010) (Fig. 21.1).

\section{Lessons from an AIP ${ }^{+/}$Mice Model}

The homozygous $A I P^{-/-}$knockout mice model reported by Lin et al. (2007) displayed severe developmental abnormalities and embryonic lethality but no recognized pituitary phenotype. However, the pituitary gland was not studied. Recently, the heterozygous $A I P^{+/-}$mice model developed by Raitila et al. (2010) proved to develop pituitary tumors with a full penetrance. Such a high penetrance might be partially explained by the spontaneous development of PA in this strain of mice, since up to $40 \%$ of wild-type controls were also affected - mostly by prolactinomas - between 6 and 18 months-old. In contrast, $100 \%$ of $A I P^{\mathrm{mut}}$ animals developed PA - 80\% somatotropinomas - from 3 to 15 months-old, with $A I P^{\text {mut }}$ tumors being more aggressive and displaying a higher proliferative index than spontaneous tumors. These observations clearly support the tumor suppressing role of AIP in somatotrophs.

\section{AIP, AHR and Other AIP-Related Proteins in the Pathogenesis of Pituitary Adenomas}

\section{Pituitary Expression of AIP}

The interest towards the pituitary expression of AIP in the normal pituitary and its biological significance was born with its identification as a new pituitary tumor suppressing gene. Studies by Leontiou et al. (2008) and Jaffrain-Rea et al. (2009) have clearly shown an abundant expression of AIP in normal human pituitaries and indicated a topographic distribution largely overlapping that of GH-secreting cells, other AIP- expressing cells being mostly lactotrophs. This phenotypic characterization was confirmed by ultrastructural studies which also localized AIP in hormone-secreting granules. In contrast with the restricted expression of AIP in the normal pituitary, both groups have observed a potential, though heterogeneous, expression of AIP in all PA phenotypes. According to Real-Time RT-PCR analysis and immunohistochemical studies, the highest levels of AIP expression were observed in somatotropinomas, but also, unexpectedly, in non-functioning pituitary adenomas (NFPA). In $A I P^{m u t}$ tumors, AIP expression was typically down-regulated, due to hemizigosity, but the mutated protein could be readily detected in most cases. Intriguingly, we also noticed that AIP down-regulation was frequent in aggressive somatotropinomas, regardless of AIP mutations, and in the vast majority of prolactinomas, including microprolactinomas. These findings support a potential role for AIP in the pathogenesis of sporadic somatotropinomas, and suggest that, in addition to germline mutati ons, currently unrecognized mechanisms are responsible for AIP loss of expression in tumorous somatotrophs and lactotrophs.

\section{The AIP Protein: From Structure to Function}

The AIP protein, also known as ARA9/XAP2, is composed in humans of 330 aminoacids, with a high degree of conservation among species. Its expression starts in the embryo, and is nearly ubiquitous in the adult. From a functional point of view, its N-terminal half contains a FK506 binding peptidyl-prolyl cis-trans isomerase (PPI) domain sharing elevated homology with immunophilins of the FKBP52 class, whereas its C-terminal half contains three tetratricopeptide (TPR) domains, typically involved in proteinprotein interactions, and a C-terminal $\alpha$-helix (Carver et al. 1998). Therefore, AIP looks like a complex regulatory protein, able to indirectly modulate a number of cellular pathways and functions. Already characterized protein partners of AIP include: (1) the Aryl Hydrocarbon Receptor (AhR, also known as the "dioxin recep- 
tor") itself, a member of the bHLH/PAS (basic Helix-Loop-Helix/Per-Arnt-Sim) family of transcription factors involved in cell response to polycyclic aromatic hydrocarbons but also in developmental processes and the regulation of cell cycle and differentiation, which unliganded form is stabilized in the cytoplasm in a multimeric AIP/AhR/Hsp90 complex; (2) the phosphodiesterases PDE4A5 and PDE2A, which are implicated in the cAMP signaling pathway; (3) the anti-apoptotic factor survivin and Ret, which prevents the formation of the AIP/survivin complex; (4) members of the steroid receptor superfamily such as PPAR- $\alpha$, the $\beta$-thyroid hormone receptor 1 (TR $\beta 1)$ and the glucocorticoid receptor; (5) additional proteins among which viral proteins and proteins involved in mitochondrial import (Ozfirat and Korbonits 2010 and Jaffrain-Rea et al. 2010a).

The molecular pathways involved in AIPrelated pathogenesis have not been elucidated yet, but in vitro experiments on the rat lactosomatotroph cell line $\mathrm{GH}_{3}$ have clearly shown that overexpression of the wild-type AIP gene reduces its proliferation rate, whereas the transfection of some $A I P^{m u t}$ genes inhibits this effect (Leontiou et al. 2008) and AIP gene silencing had a proproliferative effect (Heliövaara et al. 2009). This is in agreement with the proliferative index observed in the $A I P^{+/-}$mice model cited hitherto (Raitila et al. 2010). Because most AIP mutations described so far may theoretically disrupt one or more functional interactions of AIP, we will now analyse which mechanisms could be the most attractive for pituitary tumorigenesis.

\section{AIP and the Regulation of AHR Signalling}

The best characterized function of AIP is to interact with the AhR/dioxin receptor and contributes to its stabilization in a AIP/AhR/hsp90/p23 cytoplasmic complex. The classical pathway for AhR activation is initiated by the binding of exogenous ligands such as dioxin and aromatic hydrocarbons. This stimulates the nuclear translocation of $\mathrm{AhR}$ and its heterodimerization with the closely related ARNT (AhR Nuclear Translocator, also known as the Hypoxia-Inducible Factor $1 \beta$, HIF1 $\beta$ ). The AhR/ARNT complex then binds DNA consensus sequences known as XRE (xenobiotic-) /DRE(dioxin-response elements) localized in the promoter of responsive genes, recruits coactivator molecules and stimulates the transcription of a number of genes, including detoxifying enzymes which mediate the toxic response and genes involved in cell cycle control. The activated AhR is then quickly exported to the cytosol where it is degradated by the proteasome, hence preventing constitutive activity. There is also accumulating evidence for nucleo-cytoplasmic shuttling of AhR in the absence of exogenous ligands. Such findings, together with the ancestral and highly conserved expression of AhR, and the developmental abnormalities and diseases observed in the AhR null mice, clearly point to endogenous functions, which likely represent the key role of AhR during evolution and are supported by the report of an increasing number of potential endogenous activators of AhR. The complex control of gene expression by AhR and the potential crosstalk of AhR-related pathways with other signalling pathways, including hormone signalling, have been recently reviewed in details by Beischlag et al. (2008) and Puga et al. (2009), respectively. We will therefore attempt to evaluate their potential relevance to pituitary tumorigenesis.

\section{AHR and the Pituitary Gland}

The AhR is widely expressed in endocrine tissues, and its activation by exogenous dioxinrelated compounds has been shown to potentially modulate pituitary function. Elango et al. (2006) reported that in vitro exposure of rainbow trout pituitary cells to $2,3,7,8$ tetrachlorodibenzo- $p$ dioxin (TCDD) induces GH and prolactin (PRL) secretion, in part through AhR-mediated transcriptional effects. Dioxin is also able to interfere with both the hypothalamic-pituitary-adrenal and hypothalamic-pituitary-gonadal axis, but no clear-cut effect has been reported on normal adult corticotrophs or gonadotrophs in vitro. 
Surprisingly, dioxin exposure appears to reduce the incidence of spontaneous PA in the rat, but not in humans.

We have recently studied the expression of $\mathrm{AhR}$ in the normal human pituitary and in a subset of human PA, including AIP ${ }^{\text {mut }}$ tumors, by Real-Time RT-PCR and immunohistochemistry (Jaffrain-Rea et al. 2009). The expression of AhR was lower than observed for AIP, but tended to have a broader phenotypic distribution. We used two anti-AhR antibodies, one monoclonal directed against a $\mathrm{N}$-terminal epitope of the protein, near the DNA-binding domain, and one polyclonal against the $\mathrm{C}$-terminal half of the protein, respectively. The first one showed a selective cytoplasmic immunostaining, which was significantly correlated with AIP expression, thereby supporting a role for AIP in the stabilization of AhR in the pituitary as reported in other tissues. Accordingly, cytoplasmic AhR expression was down-regulated in most $A I P^{m u t} \mathrm{PA}$ and in nonAIP ${ }^{\text {mut }}$ PA displaying a low AIP expression. Nuclear immunostaining was best revealed by the C-terminal antibody, possibly due to epitope masquerading using the $\mathrm{N}$-terminal antibody, but restricted to a minority of cases - mostly somatotropinomas and some AIP-expressing NFPA-. In contrast with Heliovaara et al. (2009) who reported nuclear AhR immunostaining in a subset of $A I P^{\text {mut }} \mathrm{PA}$, this was not observed in our series. These data suggest that AhR signalling might be differentially regulated in PA, depending on phenotype and AIP status.

Down-regulation of the AhR partner ARNT has been observed in $\sim 50 \%$ of the human AIP ${ }^{m u t}$ PA studied by Heliovaara et al. (2009), and further supported by studies in the $A I P^{+/-}$mice model developed by the same group (Raitila et al. 2010). In this model, AIP expression was lost in almost all PA arising in $A I P^{+/-}$animals, due to $\mathrm{LOH}$, and accompanied by loss of ARNT and/or its homologue ARNT2 in most cases (>90\%). In contrast, AIP, ARNT and ARNT2 expression were maintained in all PA arising in the control mice. The biological significance of these findings remains unclear, since AhR expression was not reported in this model and an alternative partner of ARNT/ARNT2, the Hypoxia-Inducible Factor
HIF1 $\alpha$, was similarly expressed in AIP-proficient and $A I P$-deficient PA, respectively.

\section{AHR, the Cell Cycle and Tumorigenesis}

Molecular mechanisms linking AhR to cell cycle regulation are of great pathological interest since AhR has been potentially implicated in cancer in several ways: (1) dioxin is a well-recognized carcinogen - with no specific site of tumor induction - and most effects of dioxin and related compounds are mediated by AhR; (2) overexpression of AhR has been reported in human cancers, such as breast cancer and melanoma. On the other hand, AhR down- regulation has also been observed in a minority of tumors (i.e. acute lymphocytic leukaemia) and exogenous stimulation of AhR has variable effects on cell proliferation. Indeed, in most cases a growth-suppressing effect of exogenous AhR activation is observed, and this is mediated by an induction of the CDKI $\mathrm{p} 27^{\mathrm{Kip} 1}$ through AhR/ARNT binding on a DRE element. ARNT is absolutely required for this effect, and pRB has also been proposed as a co-activator. The interaction of AhR with $\mathrm{pRb}$ has been well documented: AhR interacts with hypophosphorylated $\mathrm{pRb}$ through at least two distinct $\mathrm{pRb}$ binding domains and synergizes with $\mathrm{pRb}$ to repress the transcription of E2F-induced genes such as cyclin E, cdk2, DNA polymerase $\alpha$ and S-phase enzymes. Thus, AhR activation may arrest the cell cycle in G1/S. Because this effect requires $\mathrm{pRb}$, it is lost in abnormal $\mathrm{pRb}$-deficient cells. On the other hand, because E2F-1 is a proapoptotic member of the E2F family, which is able to arrest cells in $\mathrm{G} 2 / \mathrm{M}, \mathrm{AhR}$ can also inhibit the pro-apoptotic response by binding E2F-1 and promote cell survival. This occurs in the presence of DNA damage, when E2F-1 is stabilized in its active for by ATM/ATR and Chk2 phosphorylation. This dual control on the cell cycle has been reported by Marlowe and Puga (2005) as the "ying-yang" effect of AhR. There is also considerable evidence that endogenous AhR has a proproliferative potential. A possible explanation to this phenomenon has been provided recently on breast cancer cell lines, showing that endogenous 
AhR forms a complex with cyclinD/cdk4 enhancing $\mathrm{pRb}$ phosphorylation, whereas stimulation by exogenous ligands disrupts such interaction and promotes $\mathrm{pRb}$ effects on the repression of E2Finduced genes (Barhoover et al. 2010). Therefore, it has become more and more evident that the final effect of AhR activation on cell growth, differentiation and apoptosis depends on a series of factors, including the presence or the absence of exogenous ligands, and cell phenotype, status and environment (Puga et al. 2009). On the other hand, the induction of early response oncogenes by dioxin and related compounds, which participate in their tumorigenic effects, does not appear to be dependent on AhR/ARNT transcription. To summarize, AhR generally induces growth arrest in the presence of exogenous ligands, whereas in the absence of exogenous ligands, it may exert an anti-apoptotic, prosurvival effect.

It is worth noting that the activation of $\mathrm{AhR}$ is also regulated by phosphorylation in its $\mathrm{C}$-terminal half, which provides a further level of crosstalk between AhR and extracellular signalling linked to cell growth, differentiation and apoptosis. This phenomenon has been recently reviewed by Henkovà et al. (2008). Briefly, mitogen-activated protein kinases (MAPKs), which can be activated by a variety of growth factors, cytokines, and cellular stressful events including genotoxic and oxidative stress, are able to differentially modulate AhR subcellular localization, transcriptional activity and protein stability. Conversely, exogenous ligands of AhR have also been found to activate MAPKs. Whether the interplay between MAPKs and AhR signalling is relevant to pituitary tumorigenesis warrants further investigation, since MAPKs - especially the Extracellular Regulated Kinases ERK1/2, which can directly associate with AhR - have been involved in pituitary tumorigenesis (Cakir and Grossman 2009).

Finally, it should be noticed that the transcription factors RelA and RelB, which are involved in the inflammatory response but also in the regulation of cell survival and apoptosis induced by cytokines, are also able to dimerize with AhR, and cross-talk has been established between exogenous AhR activation and NFkB signalling (Beischlag et al. 2008).

\section{AHR, AIP and the Modulation of Nuclear Endocrine Signalling}

Among the multiple cross-talks involving AhR signalling, is able the best characterized is endocrine disruption, which is believed to account for the reported effects of dioxin and related compounds on thyroid function, sexual development and function, fertility, and some endocrine-related cancers such as testicular cancer. Several lines of evidence suggest that AhR is able to mediate offtarget or non-DNA binding dependent transcription. The potential role of AIP in the endocrine disrupting effects of AhR is unclear, but AIP itself has been reported to interfere with steroid receptor activity - i.e. inhibition of glucocorticoid receptor activity through direct AIP/GR/ Hsp90 interaction (Laenger et al. 2009) -, further enhancing the complexity of endocrine modulation by the AIP/AhR system.

\section{AHR and Endocrine Disruption}

Dioxin is a major endocrine disruptor. It reduces estrogen signalling in many ways including (1) increased estrogen metabolism through the CYP1a/b and CYP19/aromatase enzymes, (2) increased ER $\alpha$ degradation, (3) reduced ER transcriptional activity due to DRE upstream to ERE in target gene promoters, direct competition on ERE binding or for the recruitment of common co-activators (squelching). Also, both AhR and ARNT are able to directly interact with the ER, and ER may be recruited on active DRE elements and enhance AhR transcription, whereas ER signalling in itself is reduced (Beischlag et al. 2008). The endocrine disrupting effects of dioxin-related compounds as industrial pollutants have been widely studied in fish species because of their impact on sexual development and fertility. Elango et al. (2006) have observed, in the rainbow trout pituitary, that both estradiol and TCDD were able to stimulate GH and PRL transcription in a dose-dependent manner. The estrogenic effects of TCDD were observed only in the absence of E2 and strongly reduced by the addition of an AhR antagonist. This can be explained 
by binding of the activated AhR/ARNT to the unliganded $E R \alpha / \beta$, which results in the recruitment of unliganded ER and the co-activator p300 to ERE, with subsequent activation of gene transcription and oestrogenic effects. In contrast, in the presence of both TCDD and $\mathrm{E}_{2}$, PRL transcription was lower than in controls, confirming endocrine disruption (transrepression). Additional nuclear partners of AhR have been reported, including the androgen receptor and TR, potentially interfering with endocrine signalling.

The observation that AIP ${ }^{\text {mut }}$ PA are more frequent and more severe in male patients - gigantism and resistant macroprolactinomas have been reported in males - is intriguing and yet unexplained. Studies from our laboratory have shown that PA express sex steroid hormones receptors with a differential pattern according to phenotype and patient's gender and gonadal function (Jaffrain-Rea et al. 1996), and that sex steroids are able to modulate their proliferation in vitro accordingly (Caronti et al. 1995). In particular, ER expression was higher in male prolactinomas and $17 \beta$-estradiol had a proliferative effect on most ER-expressing PA. It is tempting to hypothesize that abnormal crosstalk between sex steroids and AhR signalling in AIP-deficient cells might contribute to gender-related variations in tumor phenotype.

\section{Interactions of AIP and AHR with PPAR $\alpha$}

AIP is able to interact with PPAR $\alpha$ which, unlike other type II steroid receptors, may be present in a latent form and form a complex with AIP and hsp90 (Sumanasekera et al. 2003). Like AhR, PPAR $\alpha$ can be activated by endogenous or exogenous ligands, and exerts complex transcriptional effects which are highly dependent on cell type and environment. The transcriptional effects of PPAR agonists are mediated through PPAR/RXR heterodimers binding to the consensus sequences PPREs. A stimulating effect of PPAR $\alpha$ agonists on PRL transcription and secretion has been reported in $\mathrm{GH}_{4} \mathrm{C}_{1}$ cells, which is believed to be indirect and dependent on Pit-1 activation and recruitment of co-activators (Tolon et al. 1998).
Interestingly, AIP inhibits the transcriptional activity of PPAR $\alpha$, suggesting that loss of AIP function or expression in Pit-1-dependent cells may contribute to AIP-related pathogenesis. In addition, PPARs are affected by dioxin and related compounds in an AhR-dependent manner, and PPAR $\alpha$ agonists may either potentiate or repress CYP1A genes transcription according to the cellular context (Beischlag et al. 2008). The potential effects of the AhR alterations reported in pituitary cells on PPAR $\alpha$ signalling are unknown.

\section{AIP, AHR and the Modulation of the CAMP Pathway}

The cAMP-protein kinase A (PKA) pathway is essential for somatotrophs and lactotroph cells. In somatotrophs, it stimulates hormone secretion and cell proliferation and is positively and negatively regulated by the hypothalamic GrowthHormone Releasing Hormone (GHRH) and somatostatin (SMS), respectively, whereas lactotrophs are under physiological inhibition by hypothalamic dopaminergic signalling. Constitutive activation of the cAMP pathway has been involved in the pathogenesis of sporadic pituitary tumorigenesis and inherited forms of somatolactotroph adenomas and/or hyperplasia in the setting of Carney complex or McCune Albright syndrome (Boikos and Stratakis 2007). Transgenic GHRH mice develop somatotroph hyperplasia and adenomas, and in humans activating mutations of the Gsalpha subunit gene (GNAS1) are the most common somatic mutations observed in somatotropinomas. Conversely, somatostatin analogues and dopamine-agonists are widely used in the pharmacological treatment of human somatotropinomas and prolactinomas, respectively. Upon ligand activation, specific receptors for these drugs - the somatostatin receptors SSTR $1,2,3,5$ and the dopamine-agonist receptor D2R - inhibit the adenylate cyclase/cAMP/ PKA pathway, resulting in reduced hormone secretion and, to a variable extent, tumor shrinkage. Whether the unusual rate of pharmacological resistance observed in AIP ${ }^{m u t} \mathrm{PA}$ is due to some alteration in 
cAMP-related pathways remains to be defined, but both AIP and AhR have been reported to modulate cAMP signalling in non pituitary models and some findings could be potentially extended to pituitary cells.

On one hand, cAMP is considered as a nonligand endogenous activator of $\mathrm{AhR}$, able to stimulate its translocation to the nucleus similarly to dioxin, although in this case nuclear AhR does not appear to dimerize with ARNT or induce CYP1A transcription, but rather forms a complex with yet unidentified proteins. Thus, cAMP itself or some event downstream cAMP may modulate the response to $\mathrm{AhR}$ and act as a repressor rather than an activator of classical AhR-dependent gene expression. On the other hand, AIP has been shown to interact with some phosphodiesterases (PDEs), which inactivate cyclic nucleotides, and this may modulate cAMP concentration and/or AhR nuclear translocation and transcriptional activity. Such mechanisms have been recently reviewed by de Oliveira and Smolenski (2009). Briefly, a direct interaction of AIP with the isoforms PDE4A5 and PDE2 has been demonstrated, which is mediated by its TPR domains. PDE4 phosphodiesterases are involved in cAMP degradation and induced by PKA (and ERK). Binding to AIP appears specific of the PDE4A5 isoform, and results in a dramatic decrease in its enzymatic activity. As shown by Leontiou et al. (2008) and further supported by work from the same group (Igreja et al. 2010) a number of germline AIP mutations have proven to lose the ability to interact with PDE4A5. Intriguingly, disruption of AIP/PDE4A5 interaction should lead to reduced intracellular cAMP concentrations. PDE2 is induced by cGMP and involved in the regulation of cAMP and cGMP concentrations. Interaction with AIP has no effect on its enzymatic activity, but PDE2 inhibits nuclear AhR translocation, likely as a result of local regulation of cAMP concentration. The effects of AIP mutations on AIP/PDE2 interaction have not been determined yet. Potential alterations in the cAMP pathway in the presence of abnormal AIP or AhR expression and function should be further investigated.

\section{AIP and the RET/Survivin Interaction}

It was recently reported by Vargiolu et al. (2009) that AIP is able to interact with survivin, an antiapoptotic protein, and the tyrosine kinase receptor Ret. In this model, interaction of AIP with Ret prevents the stabilization of survivin by AIP. This represents an interesting potential link between AIP and cell survival, and an anti-apoptotic role of AIP may be hypothesized for example in NFPA expressing AIP. The Ret receptor is activated by the Glial-Derived Neurotrophic Factor (GDNF) forming a complex with the GDNFReceptor $\alpha$ (GFR $\alpha 1)$. Japon et al. (2002) have previously shown that Ret and its 2-ligand system GDNF and GFR $\alpha 1$ are expressed in the normal pituitary, essentially by somatotrophs, and invariably detected in somatotropinomas. The biological function of Ret in somatotrophs has then been investigated by the same group, using in vitro experiments and a Ret knock-out mice model, clearly showing that Ret was able to regulate the number of somatotroph cells through a Pit-1/p53/apoptotic pathway (Cañibano et al. 2007). Although Vargiolu et al. (2009) have tested the effects of some missense AIP mutations on RET binding and found no noticeable change, truncating mutations were not studied. It is tempting to hypothesize that some AIP mutations may disrupt its interaction with Ret, thereby allowing AIP to promote pituitary cell survival through survivin stabilization and/or abnormal Ret signalling.

\section{Conclusion and Future Perspectives}

The discovery of AIP as a predisposing gene for pituitary adenomas has opened a new field in the study of pituitary tumorigenesis, offering a broad spectrum of potentially related abnormalities in molecular pathways involved in endocrine signalling as well as the control of cell proliferation and apoptosis. Some of them involve completely new players in pituitary biology - such as AhR and related molecules -, others are more familiar pathways - such as the 
cAMP-PKA pathway - to be revised at the light of new potential mechanisms of crosstalk in the pituitary gland. At the moment, the pathogenic role of the best characterized AIP partner, AhR has not been definitively proven in pituitary cells, and endocrine disruption and pathways such as PPAR and Ret signalling represent additional attractive candidates. The potential influence of AIP in the pharmacological response to the widely used somatostatin analogues and dopamine-agonist drugs should be evaluated and may provide new insights in the comprehension of pharmacological resistance in PA Preliminary data from our laboratory indicate that pre-operative treatment with SSA is associated with a higher AIP expression in sporadic, but not in AIPmut, somatotropinomas (Jaffrain-Rea et. al, 2010 b). Interestingly, unlike the MEN1 gene, which seems poorly involved in sporadic pituitary pathogenesis, AIP may also play a significant role in the pathogenesis of a subset of PA, regardless of AIP mutations. In addition, inherited predisposition linked to the $A I P$ gene is characterized by an incomplete or low penetrance, which strongly supports the need for additional factors to initiate or promote pituitary tumorigenesis and stimulates research work aimed to their identification. Another open issue remains the pituitary specificity of AIP-related neoplasia, since additional tumors have been occasionally observed in $A I P^{m u t}$ patients, and $\mathrm{LOH}$ in 11q13 with loss of the wild-type AIP allele was recently reported by Toledo et al. (2010) in an adrenocortical carcinoma operated on in an acromegalic patient with a truncating familial AIP mutation. Because AIP has a rather ubiquitous expression, the signalling pathways which are potentially disrupted by AIP mutations may be relevant for tumorigenesis in other tissues. The mice model developed by Raitila et al. (2010), genetic studies aimed at the identification of modifier loci in $A I P^{m u t}$ kindreds, new genomic and proteomic tools applied to AIP ${ }^{m u t}$ tumors and in vitro models, should help provide significant insights into AIP-related pathogenesis in a the next future.

\section{References}

Asa SL, Ezzat S (2009) The pathogenesis of pituitary tumors. Ann Rev Pathol 4:97-126

Barhoover MA, Hall JM, Greenlee WF, Thomas RS (2010) Aryl hydrocarbon receptor regulates cell cycle progression in human breast cancer cells via a functional interaction with cyclin-dependent kinase 4 . Mol Pharmacol 77:195-201

Beckers A (2010) Higher prevalence of clinically relevant pituitary adenomas confirmed. Clin Endocrinol (Oxf) 72:290-291

Beischlag TV, Morales JL, Hollingshead BD, Perdew GH (2008) The aryl hydrocarbon receptor complex and the control of gene expression. Crit Rev Eukaryot Gene Expr 18:207-250

Boikos SA, Stratakis CA (2007) Molecular genetics of the cAMP-dependent protein kinase pathway and of sporadic pituitary tumorigenesis. Hum Mol Genet 16(Spec No 1):R80-R87

Cakir M, Grossman AB (2009) Targeting MAPK (Ras/ ERK) and PI3K/Akt pathways in pituitary tumorigenesis. Expert Opin Ther Targets 13:1121-1134

Cañibano C, Rodriguez NL, Saez C, Tovar S, GarciaLavandeira M, Borrello MG, Vidal A, Costantini F, Japon M, Dieguez C, Alvarez CV (2007) The dependence receptor Ret induces apoptosis in somatotrophs through a Pit-1/p53 pathway, preventing tumor growth. EMBO J 26:2015-2028

Caronti B, Paladini G, Caldelaro C, Bevilacqua MG, Petrangeli E, Esposito V, Tamburrano G, Gulino A, Jaffrain-Rea ML (1995) Effects of gonadal steroids on the growth of human pituitary adenomas in vitro. Tumor Biol 16:353-364

Carver LA, La Pres JJ, Jain S, Dunham EE, Bradfield CA (1998) Characterization of the Ah receptor - associated protein ARA9. J Biol Chem 50:33580-33587

Daly AF, Jaffrain-Rea ML, Ciccarelli A, Valdes-Socin H, Rohmer V, Tamburrano G, Borson-Chazot C, Estour B, Ciccarelli E, Brue T, Ferolla P, Emy P, Colao A, De Menis E, Lecomte P, Penfornis F, Delemer B, Bertherat J, Wemeau JL, De Herder W, Archambeaud F, Stevenaert A, Calender A, Murat A, Cavagnini F, Beckers A (2006) Clinical characterization of familial isolated pituitary adenomas. J Clin Endocrinol Metab 91:3316-3323

Daly AF, Vanbellinghen JF, Khoo SK, Jaffrain-Rea ML, Naves LA, Guitelman MA, Murat A, Emy P, GimenezRoqueplo AP, Tamburrano G, Raverot G, Barlier A, De Herder W, Penfornis A, Ciccarelli E, Estour B, Lecomte P, Gatta B, Chabre O, Sabate MI, Bertagna X, Garcia Basavilbaso N, Stalldecker G, Colao A, Ferolla P, Wemeau JL, Caron P, Sadoul JL, Oneto A, Archambeaud F, Calender A, Sinilnikova O, Montanana CF, Cavagnini F, Hana V, Solano A, Delettieres D, Luccio-Camelo DC, Basso A, Rohmer V, Brue T, Bours V, Teh BT, Beckers A (2007) Aryl 
hydrocarbon receptor-interacting protein gene mutations in familial isolated pituitary adenomas: analysis in 73 families. J Clin Endocrinol Metab 92:1891-1896

Daly AF, Tichomirowa MA, Petrossians P, Heliövaara E, Jaffrain-Rea ML, Barlier A, Naves LA, Ebeling T, Karhu A, Raappana A, Cazabat L, De Menis E, Montañana CF, Raverot G, Weil RJ, Sane T, Maiter D, Neggers S, Yaneva M, Tabarin A, Verrua E, Eloranta E, Murat A, Vierimaa O, Salmela PI, Emy P, Toledo RA, Sabaté MI, Villa C, Popelier M, Salvatori R, Jennings J, Longás AF, Labarta Aizpún JI, Georgitsi M, Paschke R, Ronchi C, Valimaki M, Saloranta C, De Herder W, Cozzi R, Guitelman M, Magri F, Lagonigro MS, Halaby G, Corman V, Hagelstein MT, Vanbellinghen JF, Barra GB, Gimenez-Roqueplo AP, Cameron FJ, Borson-Chazot F, Holdaway I, Toledo SP, Stalla GK, Spada A, Zacharieva S, Bertherat J, Brue T, Bours V, Chanson P, Aaltonen LA, Beckers A (2010) Clinical characteristics and therapeutic responses in patients with germ-line AIP mutations and pituitary adenomas: an international collaborative study. J Clin Endocrinol Metab 95:E373-E383

De Oliveira SK, Smolenski A (2009) Phosphodiesterases link the aryl hydrocarbon receptor complex to cyclic nucleotide signaling. Biochem Pharmacol 77:723-733

Elango A, Shepherd B, Chen TT (2006) Effects of endocrine disrupters on the expression of growth hormone and prolactin mRNA in the rainbow trout pituitary. Gen Comp Endocrinol 145:116-127

Galdelha MR, Prezant TR, Une KR, Glick RP, Moskal Ii SF, Vaisman M, Melmed S, Kineman RD, Frohman LA (1999) Loss of heterozygosity on chromosome $11 \mathrm{q} 13$ in two families with acromegaly/gigantism is independent of mutations of the multiple endocrine neoplasia type I gene. J Clin Endocrinol Metab 84:249-256

Heliövaara E, Raitila A, Launonen V, Paetau A, Arola J, Lehtonen H, Sane T, Weil RJ, Vierimaa O, Salmela P, Tuppurainen K, Mäkinen M, Aaltonen LA, Karhu A (2009) The expression of AIP-related molecules in elucidation of cellular pathways in pituitary adenomas. Am J Pathol 175:2501-2507

Henklovà $\mathrm{P}$, Vrzal R, Ulrichovà J, Dvoràk Z (2008) Role of mitogen-activated protein kinases in aryl hydrocarbon signaling. Chem Biol Interact 172:93-104

Igreja S, Chahal HS, King P, Bolger GB, Srirangalingam U, Guasti L, Chapple JP, Trivellin G, Gueorguiev M, Guegan K, Stals K, Khoo B, Kumar AV, Ellard S, Grossman AB, Korbonits M, International FIPA Consortium (2010) Characterization of aryl hydrocarbon receptor interacting protein (AIP) mutations in familial isolated pituitary adenoma families. Hum Mut 31:950-960

Jaffrain-Rea ML, Petrangeli E, Ortolani F, Fraioli B, Lise A, Esposito V, Spagnoli LG, Tamburrano G, Frati L, Gulino A (1996) Cellular receptors for sex steroids in human pituitary adenomas. J Endocrinol 151:175-184

Jaffrain-Rea ML, Angelini M, Gargano D, Tichomirowa MA, Daly AF, Vanbellinghen JF, D'Innocenzo E,
Barlier A, Giangaspero F, Esposito V, Ventura L, Arcella A, Theodoropoulou M, Naves LA, Fajardo C, Zacharieva S, Rohmer V, Brue T, Gulino A, Cantore G, Alesse E, Beckers A (2009) Expression of aryl hydrocarbon receptor (AHR) and AHRinteracting protein in pituitary adenomas: pathological and clinical implications. Endocr Relat Cancer 16:1029-1043

Jaffrain-Rea ML, Daly AF, Angelini M, Petrossians P, Bours V, Beckers A (2010a) Genetic susceptibility in pituitary adenomas: from pathogenesis to clinical implications. Exp Rev Endocrinol Metab 6(2):195-214

Jaffrain-Rea ML, Angelini M, Tichomirowa MA, Theodoropoulou M, Daly AF, Barlier A, Naves LA, Fajardo C, Zacharieva S, Rohmer V, Brue T, Ventura L, Esposito V, Giangaspero F, Alesse E, Beckers A (2010 b). Factors associated with AIP expression in somatotropinomas and the possible influence of somatostatin analogues. 15th Congress of the European Neuroendocrine Association, Liège, 22-25 September 2010, Belgium.

Japón MA, Urbano AG, Sáez C, Segura DI, Cerro AL, Diéguez C, Alvarez C (2002) Glial-derived neurotropic factor and RET gene expression in normal human anterior pituitary cell types and in pituitary tumors. J Clin Endocrinol Metab 87:1879-1884

Laenger A, Lang-Rollin I, Kozany C, Zschocke J, Zimmermann N, Rüegg J, Holsboer F, Hausch F, Rein T (2009) XAP2 inhibits glucocorticoid activity in mammalian cells. FEBS Let 583:1493-1498

Leontiou CA, Gueorguiev M, van der Spuy J, Quinton R, Lolli F, Hassan S, Chahal HS, Igreja SC, Jordan S, Rowe J, Stolbrink M, Christian HC, Wray J, BishopBailey D, Berney DM, Wass JA, Popovic V, RibeiroOliveira A Jr, Gadelha MR, Monson JP, Akker SA, Davis JR, Clayton RN, Yoshimoto K, Iwata T, Matsuno A, Eguchi K, Musat M, Flanagan D, Peters G, Bolger GB, Chapple JP, Frohman LA, Grossman AB, Korbonits M (2008) The role of the aryl hydrocarbon receptor-interacting protein gene in familial and sporadic pituitary adenomas. J Clin Endocrinol Metab 93:2390-2401

Lin BC, Sullivan R, Lee Y, Moran S, Glover E, Bradfield CA (2007) Deletion of the aryl hydrocarbon receptorassociated protein 9 leads to cardiac malformation and embryonic lethality. J Biol Chem 282:35924-35932

Marlowe JL, Puga A (2005) Aryl hydrocarbon receptor, cell cycle regulation, toxicity, and tumorigenesis. J Cell Biochem 96:1174-1184

Ozfirat Z, Korbonits M (2010) AIP gene and familial isolated pituitary adenomas. Mol Cell Endocrinol 326:71-79

Puga A, Ma C, Marlowe JL (2009) The aryl hydrocarbon receptor cross-talks with multiple signal transduction pathways. Biochem Pharmacol 77:713-722

Raitila A, Lehtonen HJ, Arola J, Heliövaara E, Ahlsten M, Georgitsi M, Jalanko A, Paetau A, Aaltonen LA, Karhu A (2010) Mice with inactivation of aryl hydrocarbon receptor-interacting protein (Aip) display complete penetrance of pituitary adenomas with aberrant ARNT expression. Am J Pathol 177:1969-1976 
Sumanasekera WK, Tien ES, Turpey R, Van den Heuvel JP, Perdew GH (2003) Evidence that peroxisome proliferator-activated receptor alpha is complexed with the $90-\mathrm{kDa}$ heat shock protein and the hepatitis virus B X-associated protein 2. J Biol Chem 278:4467-4473

Thakker RV (2010) Multiple endocrine neoplasia type 1 (MEN1). Best Pract Res Clin Endocrinol Metab 24:355-370

Toledo RA, Mendonca BB, Fragoso MC, Soares IC, Almeida MQ, Moraes MB, Lourenço-Jr DM, Alves VA, Bronstein MD, Toledo SP (2010) Isolated familial somatotropinoma: 11q13-LOH and gene/protein expression analysis suggests a possible involvement of AIP also in non-pituitary tumorigenesis. Clinics (Sao Paulo) 65:407-415
Tolon RM, Castillo AI, Aranda A (1998) Activation of the prolactin gene by peroxisome proliferator-activated receptor $\alpha$ appears to be DNA binding-independent. J Biol Chem 41:26652-26661

Vargiolu M, Fusco D, Kurelac I, Dirnberger D, Baumeister R, Morra I, Melcarne A, Rimondini R, Romeo G, Bonora E (2009) The tyrosine kinase receptor RET interacts in vivo with aryl hydrocarbon receptor-interacting protein to alter survivin availability. J Clin Endocrinol Metab 94:2571-2578

Vierimaa O, Georgitsi M, Lehtonen R, Vahteristo P, Kokko A, Raitila A, Tuppurainen K, Ebeling TM, Salmela PI, Paschke R, Gundogdu S, De Menis E, Makinen MJ, Launonen V, Karhu A, Aaltonen LA (2006) Pituitary adenoma predisposition caused by germline mutations in the AIP gene. Science 312:1228-1230 